\title{
Uso de Ratos de Laboratório para Determinar o Valor Nutritivo do Milho em Diversos Níveis de Carunchamento
}

\section{Luís Gustavo Tavares Braga1, Darci Clementino Lopes², Neuza Maria Brunoro da Costa², Jamilton Santos Pereira ${ }^{3}$, Michella da Paschoa Teixeira ${ }^{4}$}

\begin{abstract}
RESUMO - Com o objetivo de avaliar os efeitos do milho carunchado e a qualidade de sua proteína para ratos em crescimento foi conduzido um experimento no biotério do Departamento de Nutrição/UFV. Trinta ratos (fêmeas) recém-desmamados, da linhagem Wistar, com 22 dias de idade e peso médio de 53,9 3,2 g foram distribuídos em delineamento inteiramente casualizado para cinco tratamentos e seis repetições com um animal por unidade experimental. Os tratamentos consistiram de uma dieta basal (controle positivo), como um padrão de caseína, quatro dietas com milho que continha 2\%; 10\%; 17\% e 38\% de carunchamento e uma dieta isenta de proteína. O ensaio teve duração de 14 dias. Foram observados maior ganho de peso médio diário (GPMD), maior consumo de ração médio diário (CRMD), melhor conversão alimentar (CA) e maior razão protéica líquida (NPR) nos ratos que receberam a dieta padrão de caseína do que nas dietas que continham o milho carunchado, mas não foi observado diferença entre as dietas que continham diferentes níveis de carunchamento. Por outro lado, foi observado maiores coeficientes de digestibilidade de MS, PB e EDque na dieta padrão de caseína do que nas dietas contendo milho carunchado, embora maiores coeficientes tenham sido observados com $17 \%$ e que os valores semelhantes entre 2 e $38 \%$ provavelmente estejam relacionados ao processo de carunchamento. Com base nos dados do experimento, pode-se concluir que o aumento do nível de carunchamento do milho não afetou o desempenho dos animais e que a razão protéica líquida (NPR) do milho foi, em média, $57,8 \%$ do valor da dieta padrão de caseína. As variações observadas nos coeficientes de digestibilidade do milho podem ser atribuídos ao processo de carunchamento.
\end{abstract}

Palavras-chave: qualidade, proteína, NPRP, ratos, milho carunchado

\section{Use of Laboratory Rats to Determinate the Corn Nutritive Value at Several Rotten Levels}

\begin{abstract}
An experiment in the biotherium of Nutrition Department/UFV aiming to evaluate the effects of rotten corn and the quality of your protein for growing rats. Thirty Wistar female rats early weaned, with 22 days of age and average initial weight of 53.9 $\pm 3.2 \mathrm{~g}$ were assigned to a randomized design. With five treatments and six repetitions with one animal by experiment unity. The treatments consisted in a basal ration (positive control), like a casein standard, four rations with corn that had $2 \% ; 10 \%, 17 \%$ and $38 \%$ of rotten corn, and an absent protein ration. The experimental period lasted was 14 days. It was observed higher daily weight gain (DWG), higher daily feed intake (DFI), better feed: gain ratio and bigger net protein ration (NPR), in the rats that received a standard ration of casein than the rats that had a rotten corn, but no difference was observed among rations that had different levels of rotten. In other way, were observed a bigger digestibility coefficients of dry matter (DM), crude protein (CP) and digestible energy (DEin the standard casein ration than rations that had a rotten corn, although higher coefficients had bun observed with $17 \%$ and that the similar values bitwen $2 \%$ and $38 \%$ were probably related to the rotten process. Based on the experiment data, it may be conclude that the increase in the level of rotten did not affect the performance of the animals and that the NPR of the corn was $57.81 \%$ of the c standard casein level. The variations observed in the digestibility of the coefficients of the corn may be attributedto the rotten process.
\end{abstract}

Key Words: quality, protein, NPR, rats, rotten corn

\section{Introdução}

Na formulação de ração, o milho constitui sempre a maior parte, chegando a superar $70 \%$ do total, por isto, os cuidados com a sua qualidade devem ser considerados de grande importância. As grandes empresas possuem setores específicos para avalia- rem a qualidade do milho, quanto ao ataque de insetos, impurezas, micotoxinas e outros.

Entre os fatores que contribuem para a perda de qualidade dos grãos citam-se o ataque de insetos como caruncho (Sitophilos zeamais) e a traça (Sitotrogacereallella), pássaros, roedores e fungos, além da ocorrência de colheitas com alta umidade.

1 Professor Adjunto da Universidade Estadual de Santa Cruz-BA. E.mail: gbraga@uesc.br

2 Professor da Universidade Federal de Viçosa. E.mail: dclopes@ufv.br

3 Pesquisador CNPMS/EMBRAPA - Sete Lagoas - MG.

4 Estudante de Mestrado em Zootecnia/UFV. E.mail: michellapt@yahoo.com.br 
Quando ocorre o ataque de insetos, entre as conseqüências, são observadas a perda de peso e a predisposição dos grãos à infestação de fungos e a produção de micotoxinas.

Santos et al. (1988), em levantamento anual do Estado de Minas Gerais, observaram, nos meses de agosto, novembro e março após ano de colheita, níveis de 17,$3 ; 36,4$; e 44,5\% de carunchamento, correspondendo a 3,$1 ; 10,4$; e $14,3 \%$ de perda de peso, respectivamente.

O grão de milho pode ser dividido em três partes: pericarpo, endosperma e embrião. A composição bromatológica do grão varia de acordo com o tipo de semente, solo, fertilidade e condições climáticas. As proteínas do milho são divididas em albumina, globulinas, prolaninas e glutelinas, distribuídas em todas as partes dos grãos, porém a maior quantidade está no endosperma (75\%), mas a maior concentração está no germe (Sgarbieri, 1996).

No milho comum, a proteína predominante no endosperma e a zeína e no germe ou embrião são as glutelinas. Segundo Sgarbieri (1996), a zeína representa cerca de $50 \%$ da proteína do milho e é rica em prolina, leucina, alanina, glutamina e metionina, sendo pobre em lisina e triptofano e as glutelinas são ricas em lisina e triptofano. Assim, a composição de aminoácidos essenciais do endosperma apresenta valores significativamente maiores para metionina, cistina, leucina e treonina. Como o aumento do nível do carunchamento provoca elevação no teor de proteína do milho (Irabagon, 1959; Lopes et al., 1988; Vilela et al., 1988) e que esta elevação é devido ao maior consumo do endosperma pelos carunchos e como conseqüência há redução no teor de metionina e cistina como demonstrado por Souza (1999). Em testes com a alimentação de ratos albinos Irabagon (1959) verificou que o milho carunchado, com 25,9\% de redução no seu peso, praticamente não apresenta valor nutritivo para ratos.

Diante do exposto, propôs-se este experimento com o objetivo de avaliar o valor nutritivo e a qualidade da proteína do milho carunchado com ratos em crescimento.

\section{Material e Métodos}

Na primeira etapa, o milho da variedade $\mathrm{Br} 201$ foi dividido em três lotes, sendo o primeiro mantido isento de carunchamento, constituindo o nível de $2 \%$; o segundo armazenado em silo metálico com palha e sabugo, onde se obteve a infestação de $38 \%$ e o terceiro foi submetido à infestação artificial pelo caruncho (Sitophilus zeamais) para obtenção dos níveis de 10 e $17 \%$ de carunchamento.

Foi considerado carunchado, todo grão que apresentava pelo menos uma perfuração pelo inseto. Assim, elaborou-se quatro lotes de milho com 2; 10; 17 e $38 \%$ de carunchamento.

Para condução do experimento sobre desempenho, avaliação de qualidade protéica do milho e digestibilidade de seus nutrientes, 30 ratos (fêmeas) recém-desmamados, de linhagem Wistar com 22 dias de idade e peso médio de 53,9 $\pm 3,2 \mathrm{~g}$, foram distribuídos em um delineamento inteiramente casualizado para cinco tratamentos e seis repetições. Os tratamentos foram constituídos de:

T1 - Dieta com o milho a $2 \%$ de carunchamento

T2 - Dieta com o milho a $10 \%$ de carunchamento

T3 - Dieta com o milho a $17 \%$ de carunchamento

T4 - Dieta com o milho a $38 \%$ de carunchamento T5 - Dieta padrão de caseína

Usou-se ainda uma dieta isenta de proteínas, para proceder o cálculo da razão protéica líquida (NPR). As dietas foram formuladas segundo as recomendações de Reeves et al. (1993) e a composição centesimal e química das dietas encontram-se na Tabela 1.

Os animais foram alojados em gaiolas individuais colocadas em uma sala de alvenaria totalmente fechada, dotada de sistema de aquecimento e resfriamento para que a temperatura ambiente fosse mantida em $23^{\circ} \mathrm{C}$, e com um sistema de iluminação para um programa de luminosidade alternada de $12 \mathrm{~h}$ de escuro e $12 \mathrm{~h}$ de claro. Água e ração foram fornecidas à vontade. As gaiolas tiveram os fundos forrados com papelão que possibilitou a coleta total de fezes. As fezes eram acondicionadas em sacos plásticos e armazenadas em freezer a $-10^{\circ} \mathrm{C}$. Diariamente, controlava-se a temperatura e o consumo de ração. Os animais foram pesados no início e no final do experimento aos 14 dias.

Para o estudo de digestibilidade dos nutrientes utilizou-se $0,5 \%$ de óxido crômico na ração como marcador no início e no final do período de coleta que foi de 5 dias ( $7^{\underline{O}}$ ao $12^{\underline{O}}$ dia). A metodologia empregada foi a de coleta total de fezes.

As análises de matéria seca (MS) e proteína bruta (PB) foram realizadas segundo metodologia descrita por Silva (1990), a energia bruta (EB) foi determinada em calorimetria adiabática tipo Parr (1271).

O cálculo de quociente de eficiência ou razão 
Tabela 1 - Composição de ingredientes e nutrientes das dietas experimentais

Table 1 - Composition of ingredients and nutrients of the experiamental diets

\begin{tabular}{|c|c|c|c|c|c|c|}
\hline \multirow[b]{2}{*}{$\begin{array}{l}\text { Ingrediente }(\mathrm{g} / 100 \mathrm{~g}) \\
\text { Ingredient }\end{array}$} & \multicolumn{4}{|c|}{$\begin{array}{c}\text { Teor de carunchamento }(\%) \\
\text { Decayed corn level }(\%)\end{array}$} & \multirow[t]{2}{*}{$\begin{array}{l}\text { Padrão caseína } \\
\text { Casein standard }\end{array}$} & \multirow[t]{2}{*}{$\begin{array}{l}\text { Aprotéica } \\
\text { Non protein }\end{array}$} \\
\hline & 2,00 & 10,00 & 17,00 & 38,00 & & \\
\hline $\begin{array}{l}\text { Fubá de milho } \\
\text { Corn flour }\end{array}$ & 82,95 & 77,55 & 75,56 & 82,33 & - & - \\
\hline $\begin{array}{l}\text { Amido de milho } \\
\text { Corn starch }\end{array}$ & - & 5,40 & 7,39 & 0,62 & 51,32 & 59,75 \\
\hline $\begin{array}{l}\text { Amido dextrinizado } \\
\text { Dextrinized corn starch }\end{array}$ & - & - & - & - & 13,20 & 13,20 \\
\hline $\begin{array}{l}\text { Açúcar } \\
\text { Sugar }\end{array}$ & - & - & - & - & 10,00 & 10,00 \\
\hline $\begin{array}{l}\text { Óleo de soja } \\
\text { Soybean oil }\end{array}$ & 7,00 & 7,00 & 7,00 & 7,00 & 7,00 & 7,00 \\
\hline $\begin{array}{l}\text { Caseína } \\
\text { Casein }\end{array}$ & - & - & - & - & 8,43 & - \\
\hline $\begin{array}{l}\text { L-Cistina } \\
\text { L-Cystine }\end{array}$ & 0,30 & 0,30 & 0,30 & 0,30 & 0,30 & 0,30 \\
\hline $\begin{array}{l}\text { Celulose } \\
\text { Cellulose }\end{array}$ & 5,00 & 5,00 & 5,00 & 5,00 & 5,00 & 5,00 \\
\hline $\begin{array}{l}\text { Cloreto de colina } \\
\text { Cholin chloride }\end{array}$ & 0,25 & 0,25 & 0,25 & 0,25 & 0,25 & 0,25 \\
\hline $\begin{array}{l}\text { Premix vitamínico }{ }^{2} \\
\text { Vitamin mix }\end{array}$ & 1,00 & 1,00 & 1,00 & 1,00 & 1,00 & 1,00 \\
\hline $\begin{array}{l}\text { Premix mineral } \\
\text { Mineral mix }\end{array}$ & 3,50 & 3,50 & 3,50 & 3,50 & 3,50 & 3,50 \\
\hline $\begin{array}{l}\text { Total } \\
\text { Composição analisada } \\
\text { Analyzed composition }\end{array}$ & 100,00 & 100,00 & 100,00 & 100,00 & 100,00 & 100,00 \\
\hline $\begin{array}{l}\text { Energia bruta }(\mathrm{kcal} / \mathrm{kg}) \\
\text { Gross energy }\end{array}$ & 3854 & 3954 & 3869 & 3939 & 4098 & 3938 \\
\hline $\begin{array}{l}\text { Proteína bruta do milho }(\%) \\
\text { Crude protein of corn }\end{array}$ & 8,53 & 9,13 & 9,37 & 8,60 & - & $\mathrm{ND}^{1}$ \\
\hline $\begin{array}{l}\text { Proteína bruta da dieta }(\%) \\
\text { Crude protein of diet }\end{array}$ & 7,20 & 7,60 & 7,21 & 7,07 & 7,33 & ND \\
\hline $\begin{array}{l}\text { Matéria seca }(\%) \\
\text { Dry matter }\end{array}$ & 91,55 & 90,94 & 91,09 & 90,97 & 93,11 & ND \\
\hline $\begin{array}{l}1 \text { ND: não determinado (not deter } \\
2 \text { Premix vitamínico/kg: Ácido nic } \\
\text { Biotin, 0,2 mg; Vitamina B12, } 2 \\
3 \text { Premix mineral mg/kg: Cálcio, } \\
\text { Zinco, 30; Manganês, 10; Cob } \\
2 \text { Vitamin mix /kg: Nicotinic acid, } 30 \mathrm{~m} \\
25 \mathrm{mg} \text {; Vitamin E, } 75 \text { ui; Vitamin A, } \\
{ }^{3} \text { Mineral mix mg/kg: calcium, } 5000 \text {; }\end{array}$ & $\begin{array}{l}30 \mathrm{mg} ; \mathrm{Par} \\
\text { tamina } \mathrm{E} \text {, } \\
\text { osforo, } 15 \\
\text { do, } 0,2 ; \mathrm{M} \\
\text { tenate, } 15 \mathrm{~m} \\
\text { Vitamin } \mathrm{D} 3 \text {, } \\
\text { rus, } 1561 \text {; }\end{array}$ & $\begin{array}{l}\text { ato, } 15 \mathrm{mg} \text {; } \\
\text { /itamina A, } \\
\text { tássio, } 360 \\
\text { nio, } 0,15 \text {; } \\
\text { oxina, } 6 \mathrm{mg} \text {; } \\
\text {; Vitamin K, }\end{array}$ & $\begin{array}{l}\text { doxine, } 6 \\
\text { Oui; Vitam } \\
\text { nxofre, } 30 \\
\text { nio, } 0,15 . \\
\text { ina, } 5 \text { mg; } \\
\text { ng;choline, } \\
\text { 300; Sodil }\end{array}$ & $\begin{array}{l}\text { Thiamin, } 5 \\
3,1000 \text { ui } \\
\text { dio, } 1019 \text {; } \\
\text { avina, } 6 \mathrm{mg} \text {; } \\
\text { mg. } \\
\text { 19; Chlorid }\end{array}$ & $\begin{array}{l}\text { Riboflavin, } 6 \mathrm{mg} \text {; Ác } \\
\text { amina K, } 900 \mathrm{mg} ; \mathrm{co} \\
\text { acid, } 1574 \text {; Magnésio, } \\
\text { 4; Magnesium, 507; }\end{array}$ & $\begin{array}{l}\text { lo fólico, } 2 \mathrm{mg} \text {; } \\
\text { la, } 1000 \mathrm{mg} \text {. } \\
\text { 07; Ferro, 35; } \\
\text { gg; Vitamin B12, } \\
\text { n, 35; Zine, 30; }\end{array}$ \\
\hline
\end{tabular}

protéica líquida (NPR) utilizou-se a seguinte fórmula:

$$
\mathrm{NPR}=\frac{\text { Ganho de peso ajustado }(\mathrm{g})}{\text { Proteína bruta consumida }(\mathrm{g})}
$$

em que o ganho de peso ajustado foi obtido somandose ao ganho de peso de cada animal, a perda de peso dos ratos que receberam a ração isenta de proteína e o consumo de proteína foi obtido por intermédio do teor de proteína da dieta multiplicado pelo consumo total de ração de cada animal.

Os dados foram analisados pelo SAEG - Sistema de Análises Estatísticas e Genéticas (UFV, 1993) e as médias comparadas pelo teste de Student, NewmanKeuls e análise de regressão.

O modelo matemático do experimento pode ser assim apresentado:

$$
\mathrm{Y}_{\mathrm{ijk}}=\mu+\mathrm{T}_{\mathrm{i}}+\mathrm{e}_{\mathrm{ij}}
$$


em que $Y_{i j k}=$ ganho de peso, consumo de ração, razão rotéica líquida e digestibilidade dos nutrientes devido aos tratamentos; $\mu=$ média geral; $\mathrm{T}_{\mathrm{i}}=$ efeito do tratamento i ( $\mathrm{i}=1$ a 5$)$; $\mathrm{e}_{\mathrm{ij}}=$ erro aleatório

\section{Resultados e Discussão}

Os resultados referentes ao desempenho dos ratos, razão protéica líquida (NPR) das rações e digestibilidade dos nutrientes com ratos em crescimento encontram-se nas Tabelas 2 e 3.

Foram observados efeitos dos tratamentos $(\mathrm{p}<0,05)$ sobre o ganho de peso médio (GPM), consumo médio de dieta (CMD), conversão alimentar (CA), razão protéica líquida (NPR) e sobre os coeficientes de digestibilidade aparente da matéria seca (CDMS), de proteína bruta (DVPB) e sobre a energia bruta (EDA). Analisando os dados, observou-se que houve maior ganho de peso médio diário (GPMD), maior consumo de ração médio diário (CRMD), melhor conversão alimentar (CA) e maior valor de NPR dos animais que receberam a dieta padrão de caseína do que das dietas com milho carunchado, enquanto ao dados do milho carunchado não variaram entre si.

O desempenho dos ratos não foi afetado pelo aumento do nível de carunchamento, valores que não coincidirem com os verificados por Irabagon (1959), que ao trabalhar com ratos albinos constatou redução de $80 \%$ no consumo de ração quando o nível de carunchamento atingiu uma queda de peso de $25,9 \%$ no milho, por outro lado, Leandro et al. (1993) e Stringhini et al. (1993), trabalhando com aves não observaram efeitos sobre o desempenho utilizando milho com 0, 20 e $40 \%$ de carunchamento. Lopes et al. (1990) não observaram efeitos do milho com níveis crescentes de carunchamento sobre o desempenho de suínos em crescimento e terminação.

O NPR é a técnica utilizada para avaliar a qualidade da proteína de um alimento em relação ao padrão de caseína. Como pode ser observado, considerando a caseína como $100 \%$, os valores relativos obtidos para o milho carunchado foram em média $57,81 \%$, já que não variaram entre si. Assim, constatou-se que a proteína do milho é pouco superior a metade do valor de caseína. Os valores médios de NPR encontrados para o milho estão de acordo com aqueles encontrados na Literatura. Costa et al. (1996), trabalhando com ratos encontrou valores de NPR igual a $52 \%$ do valor de caseína para o milho comum e para o milho QPM este valor chegou a 70\%. Brown et al. (1988) cita que o valor de NPR do milho pode representar até $61,5 \%$ do encontrado para a caseína.

Os valores encontrados neste trabalho são semelhantes aos obtidos por Gomes et al. (2000) que trabalhando com ratos encontraram valores de NPR iguais a 4,70 para caseína, 2,70 para farelo de soja não tratada com bipiridilios, 2,60 para o tratado e 3,70 para o mesmo produto peletizado e tratado.

Benati (1972), trabalhando com poedeiras, en-

Tabela 2 - Peso médio inicial (PMI), ganho de peso médio (GPM), consumo de médio dieta (CMD), conversão alimentar média (CA) e a razão protéica líquida (NPR) de ratas no período de 14 dias de estudo ${ }^{1}$

Table 2 - Initial average weight (IAW), average gain weight (AGW), average diet intake (ADI), feed:gain ratio (FGR) and nitrogen protein liquid (NPR) of female rats in the period of 14 days of study

\begin{tabular}{|c|c|c|c|c|c|c|}
\hline \multirow[t]{2}{*}{ Item $(\%)$} & \multicolumn{4}{|c|}{$\begin{array}{c}\text { Teor de carunchamento }(\%) \\
\text { Decayed corn level }(\%)\end{array}$} & \multirow[t]{2}{*}{$\begin{array}{l}\text { Padrão caseína } \\
\text { Casein standard }\end{array}$} & \multirow[t]{2}{*}{$\mathrm{CV}$} \\
\hline & 2,00 & 10,00 & 17,00 & 38,00 & & \\
\hline $\begin{array}{l}\text { PMI (g) } \\
I A W\end{array}$ & 53,80 & 54,00 & 54,00 & 53,83 & 53,83 & 6,34 \\
\hline $\begin{array}{l}\text { GPM }(\mathrm{g}) \\
A G W\end{array}$ & $13,80 b \pm 2,82$ & $13,50 \mathrm{~b} \pm 0,71$ & $12,50 \mathrm{~b} \pm 1,48$ & $15,00 b \pm 2,12$ & $61,17 \mathrm{a}$ & 20,63 \\
\hline $\begin{array}{l}\text { CMD }(\mathrm{g}) \\
A D I\end{array}$ & $130,50 \mathrm{~b}$ & $125,50 \mathrm{~b}$ & $130,48 b$ & $140,80 \mathrm{~b}$ & $193,87 \mathrm{a}$ & 10,79 \\
\hline $\begin{array}{l}\text { CA } \\
F G R\end{array}$ & $10,01 b \pm 6,48$ & $9,54 b \pm 1,91$ & $12,20 b \pm 0,95$ & $9,41 \mathrm{ab} \pm 0,87$ & $3,46 a$ & 34,79 \\
\hline $\begin{array}{l}\text { NPR } \\
N P R\end{array}$ & $2,84 b \pm 0,41$ & $2,77 b \pm 0,42$ & $2,72 b \pm 0,20$ & $2,89 b \pm 0,02$ & 4,84 & 8,42 \\
\hline $\begin{array}{l}\text { Valor relativo de NPR }(\%) \\
N P R \text { relative value }\end{array}$ & 56,25 & 58,33 & 56,25 & 60,42 & 100 & \\
\hline
\end{tabular}

\footnotetext{
${ }^{1}$ Médias, na mesma linha, seguidas de letras diferentes, diferem entre si $(p<0,05)$ pelo teste Student-Newman-Keuls.
}

${ }^{1}$ Means within a row followed, by different letters are diferent $(p<.05)$ by Student-Newman-Keuls test. 
Tabela 3 - Coeficiente de digestibilidade aparentemente da matéria seca (CDMS), de digestibilidade verdadeira da proteína bruta (DVPB) e da energia digestível (ED) das dietas de ratos no período de 14 dias $^{1}$

Table 3 - Coefficient of apparent digestible dry matter (ADDM), true digestibility of the crude protein (TDCP) and digestible energy (DE) of the rats diets at 14 days age

\begin{tabular}{|c|c|c|c|c|c|c|}
\hline \multirow[t]{2}{*}{ Item $(\%)$} & \multicolumn{4}{|c|}{$\begin{array}{c}\text { Teor de carunchamento }(\%) \\
\text { Decayed corn level }(\%)\end{array}$} & \multirow[t]{2}{*}{$\begin{array}{l}\text { Padrão caseína } \\
\text { Casein standard }\end{array}$} & \multirow[t]{2}{*}{$\mathrm{CV}$} \\
\hline & 2,00 & 10,00 & 17,00 & 38,00 & & \\
\hline $\begin{array}{l}\mathrm{CDMS}^{2,3}(\%) \\
A D D M(\%)\end{array}$ & $85,35 \mathrm{~b} \pm 4,94$ & $80,64 \mathrm{c} \pm 1,01$ & $82,29 b c \pm 2,22$ & $85,99 \mathrm{~b} \pm 2,51$ & $91,92 \mathrm{a}$ & 4,22 \\
\hline $\begin{array}{l}\operatorname{DVPB}^{2,3}(\%) \\
\operatorname{TDCP}(\%)\end{array}$ & $89,01 \mathrm{a} \pm 6,37$ & $81,64 a b \pm 4,45$ & $75,48 \mathrm{~b} \pm 7,11$ & 87,89 a $\pm 4,30$ & $91,47 \mathrm{a}$ & 7,46 \\
\hline $\begin{array}{l}\mathrm{ED}^{2,3}(\mathrm{kcal} / \mathrm{kg}) \\
\mathrm{DE}(\mathrm{kcal} / \mathrm{kg})\end{array}$ & $3584 b$ & $3532 \mathrm{bc}$ & $3485 c$ & $3719 b$ & $4045 a$ & 4,26 \\
\hline
\end{tabular}

$1 \%$ de matéria seca.

2 Médias, na mesma linha, seguidas de letras diferentes, diferem entre si $(p<0,05)$ pelo teste SNK.

3 Efeito quadrático $(\mathrm{p}<0,05)$.

$1 \%$ dry matter.

2 Means within a row followed, by different letters are diferent $(p<.05)$ by Student-Newman-Keuls test.

${ }^{3}$ Quadratic effect $(p<.05)$.

controu valores de NPR de 47,7; 57,5; e 64,6\%, respectivamente para soja integral aquecida, integral com metionina e farelo de soja.

Como os insetos atacam primeiro o endosperma do milho que apresenta composição aminoacítica diferente do germe do milho, como afirmam Matioli \& Almeida (1979), esperavam-se algumas variações nos valores de NPR, que, entretanto, não foram detectadas neste experimento.

Os coeficientes de digestibilidade aparente de matéria seca (CDMS) e proteína bruta (DVPB) e os valores de energia digestível (ED) foram maiores com a dieta padrão de caseína do que com o milho nos diversos níveis de carunchamento, exceto para DVPB cujos valores do padrão de caseína foram semelhantes aos das dietas com 2 e $38 \%$ de carunchamento, em relação a $17 \%$ e que a dieta com $10 \%$ não diferiu ( $p>0,05)$ dos demais valores.

A análise de regressão nos dados, exceto os da dieta padrão de caseína, mostrou efeito quadrático $(\mathrm{p}<0,05)$ sobre o CDMS, DVPB e sobre os valores de ED (Figuras 1, 2 e 3), cujas equações de regressão mostraram pontos de mínimos de 18,89\% para CDMS, $20,37 \%$ para DVPB e $16,56 \%$ para ED. A redução nos valores dos coeficientes de digestibilidade, passando por um mínimo e crescendo em seguida, parece estar relacionado ao processo de carunchamento, visto que a dieta com $38 \%$ de carunchamento o milho foi estocado com palha e sabugo. Santos \& Montovani (1997) citam que, no milho armazenado com palha e sabugo, a penetração de insetos é pelo ápice dos

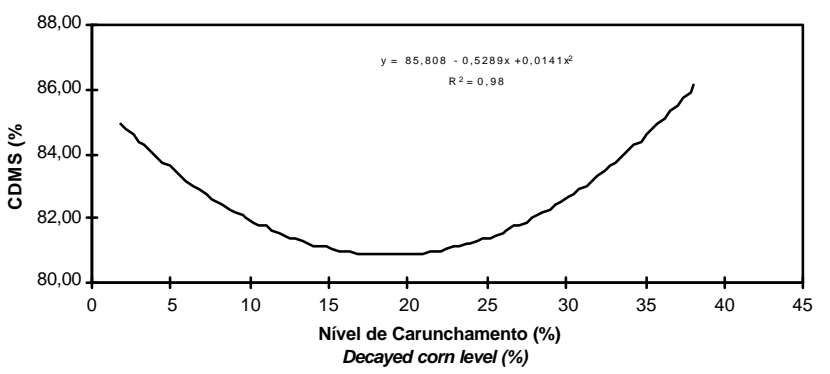

Figura 1 - Coeficiente de digestibilidade da matéria seca (CDMS) de ratos alimentados com milho carunchado.

Figure 1 - Coefficient of digestibility of dry matter (CDMS) of rats fed diets with decayed corn.

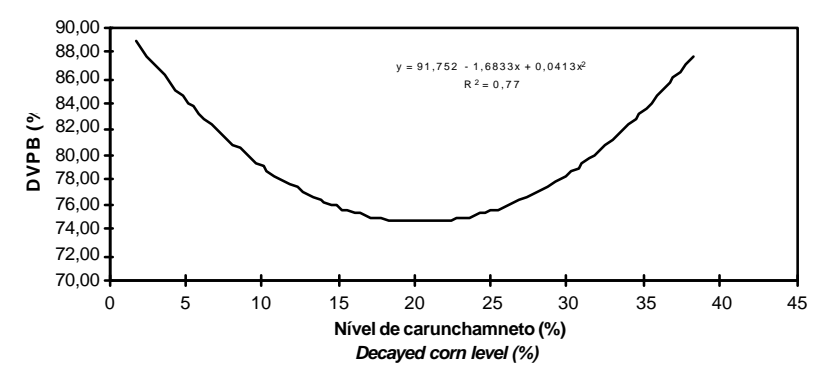

Figura 2 - Digestibilidade verdadeira da proteína bruta (DVPB) das dietas de ratos alimentados com milho carunchado.

Figure 2 - Crude protein true digestibility of (TDCP) of female rats fed diets with decayed corn. 


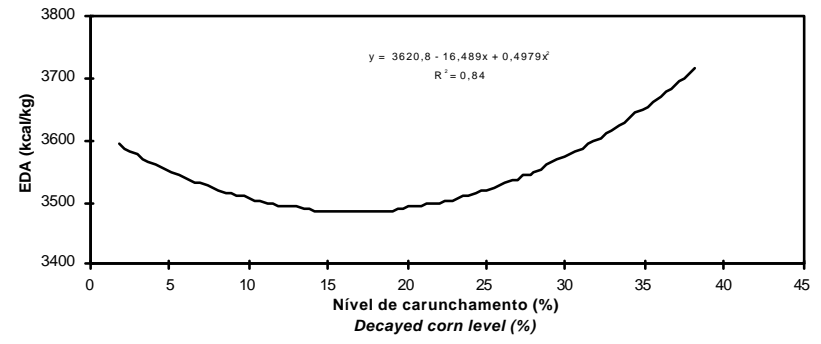

Figura 3 - Energia digestível aparente (EDA) das dietas de ratas alimentadas com milho carunchado.

Figure 3 - Apparent digestible energy (ADE) of female rats fed diets with decayed corn.

grãos e as perdas de peso por ano tem atingido em média 7\%, enquanto Campos \& Bitran (1975) mostraram que, após seis meses de estocagem, a perda de peso do milho ensacado atingiu 32,12\%, com $95 \%$ dos grãos danificados. Assim, o milho armazenado com palha e sabugo parece destruído mais lentamente do que o milho a granel.

\section{Conclusões}

Com base nos dados do experimento pode-se concluir que o aumento do nível de carunchamento do milho não afetou o desempenho dos animais e que a razão protéica líquida (NPR) do milho foi, em média, $57,8 \%$ do valor da dieta padrão de caseína. As variações observadas nos coeficientes de digestibilidade do milho podem ser atribuídos ao processo de carunchamento.

\section{Literatura Citada}

BENATI, M. Soja integral na alimentação de poedeiras. Viçosa, MG: Universidade Federal de Viçosa, 1973. 56p. Dissertação (Mestrado em Zootecnia) - Universidade Federal de Viçosa, 1973.

BROWN, W.L., BRESSANI,R., GLOVERE,D.V. et al.Quality protein. Washington, D.C.: National Academy Press, 1988. p.18-56.

CAMPOS, T.B.; BITRAN, E.A. Danos causados por gorgulhos ao milho ensacado. Ciência e cultura, v.27, n.7, p. 610-615, 1975.

CARVALHO, R.P.L. Danos, flutuação, população e resistência de genótipos a H. Zea em milho: Jaboticabal: Universidade do Estado de São Paulo, 1978. 68p. Dissertação (Livre docência) - Universidade do Estado de São Paulo, 1978.

COSTA, N.M.B.; PAES, M.C.D.; GUIMARÃES, P.E.O. Audição da qualidade protéica do milho QMP. In: CONGRESSO DA SOCIEDADE BRASILEIRA DE ALIMENTAÇÃO E NUTRIÇÃO, 4. , 1996, São Paulo.Anais... São Paulo, 1996. p.153.
GOMES, J.C.; MAGALHÃES, E.C.S.; PEREIRA, C.A.S. et al. Avaliação do efeito de bipiri (paraquat) em culturas de soja quanto às características nutricionais de proteína do farelo desengordurado. Ciências Agrotecnológicas, v.24, n.4, p.961-967, 2000.

IRABAGON, T.A. Journal Economic and Entomology, v.17, n.6, p.1130-1136, 1959.

LOPES, D.C.; FONTES, R.A.; DONZELE, J.L. et al. Perda de peso e mudanças na composição do milho (Zea Mays L.) devido ao carunchamento. Revista Sociedade Brasileira de Zootecnia, v.17, n.4, p.367-371, 1988.

LOPES, D.C.; ALVARENGA, J.C.; DONZELE, J.L.; FONTES, R.A.; VIEIRA, A.. A. Efeito do nível de carunchamento do milho sobre o desempenho de suínos em crescimento/terminação. Revista Sociedade Brasileira de Zootecnia, v.19, n.3, p.147-151, 1990.

MATIOLI, J.C.; ALMEIDA, A.A. Alterações nas características químicas dos grãos de milho causadas pela infestação do Sitophilus oryzae. Revista Brasileira de Armazenamento, v.4, p.36-46, 1979.

REEVES, P.G., NIELSEN, F.H., FAHEY JR., G.C. Ain-93 Purified diets for laboratory rodentes. Journal Nutrition. V.123, p. 1939-1951, 1993.

SANTOS, J.P.; FONTES, R.A.; CAJUEIRO, I.V.M. et al. Situação do armazenamento de milho a nível de propriedade no estado do Espírito Santo. In: Congresso Nacional de Milho e Sorgo, 16., 1986. Belo Horizonte, MG. Anais ... Sete Lagoas: EMBRAPA-CNPMS, p.237-247, 1988.

SANTOS, J.P.; MANTOVANI, E.C. Perdas de grãos na cultura do milho, pré-colheita, colheita, transporte e armazenamento: Sete Lagoas: EMBRAPA/CNPMS, 1997. 40p. (Circular Técnico 24)

SANTÚRIO, J.M. Micotoxinas na produtividade avícola: tipos, seus efeitos, como detectá-los e prevení-los. In: CONFERÊNCIA APINCO 97 DE CIÊNCIA E TECNOLOGIA AVÍCOLAS, 1997, Santos. Anais... Santos: Factor, 1997. p.224-257.

SGARBIERI, V.C. Proteínas em alimentos protéicos. São Paulo: Livraria Varela, 1996. 50p.

SILVA, D.J. Análise de alimentos (métodos químicos e biológicos). Viçosa, MG: Unversidade Federal de Viçosa, 1990. 165p.

SOUZA, A.V. Composição química e digestibilidade de nutrientes, e da energia do milho em diferentes níveis de carunchamento. Viçosa, MG: Universidade Federal de Viçosa, 1999. 56p. Dissertação (Mestrado em Zootecnia) Universidade Federal de Viçosa, 1999.

STRINGHINI, J.H.; LEANDRO, N.S.M.; ORSINE, G.F et al. 1- Avaliação de rações formuladas com milho infestado por insetos e fungos frangos de corte. 2- Milho infestado por insetos nas rações iniciais (1 a 28 dias). In: Conferência 93 Apinco de Ciência e Tecnologia Avícolas, 1993, Santos. Trabalhos de Pesquisa... Santos: 1993. p.34.

VILELA, H.; SILVA, J.F.C.; VILELA, D. et al. Alterações do valor nutritivo do grão de milho (Zea mays, L.) durante o armazenamento. Revista da Sociedade Brasileira de Zootecnia, v.17, n.5, p.428-433, 1988.

UNIVERSIDADE FEDERAL DE VIÇOSA - UFV. Central de Processamento de dados UVF/CPD. Manual de utilização do programa SAEG (Sistema para análises estatísticas e genéticas). Viçosa, MG: Universidade Federal de Viçosa, 1993. p.59. 